\title{
THE USE OF “DISPOSED” PLASTIC
}

\author{
Wolfgang E. Spoerei, M.D., F.R.C.P.(c)*
}

YEARS AGO, the anaesthetist had to construct his own equipment; it was a prerequisite for success in the specialty to have a mechanical mind. With the growth of anaesthesia an industry has grown around it to supply its needs. The frustrated inventor in the operating room has resigned himself to admire chrome and stainless steel, ready-made endotracheal tubes, and standardized connectors; rarely can his technical training come even with that of the professional engineer.

Yet the spirit of the anaesthetist has not changed. In long hours nof watchful contemplation he thinks of ways to improve his daily chore, tries to find new and better uses for his equipment, or attempts to make something new, to invent something. I should like to dedicate these few lines to this spirit and to the unknown inventor of small, perhaps unimportant, but often useful things.

In our daily work we are surrounded by disposable plastic tubings, containers, connectors, etc., all packed sterile for ready use, and once used, to be thrown out. This has undoubtedly improved the safety and efficiency of our practice. But, being old-fashioned, one looks occasionally at this waste and wonders whether there might not be a use for disposed plastic.

Many of us use discarded hospital equipment in the laboratory. The collection of used intravenous sets has been advocated to help less wealthy countries to improve their medical standards.

But then there are new ideas and uses for disposed plastic. Several self-made items have become established in this Department and are used daily. It is possible to trace only the local inventor. If a description of one or the other of the items has been published, I am not aware of it. Nor do I wish to claim any originality for myself or for members of this Department, who brought these items to my attention.

Thus, with apologies to all who have made these inventions before, I shall present here some small pieces of equiphent used in our Department, and manufactured from disposed plastic.

1. All our anaesthetic tables are equipped with a non-breakable cuff inflator, $\uparrow$ made from the drip chamber of a Baxter $\mathrm{R} 49$ transfusion set (Fig. 1). The plastic adaptor to the intravenous needle is inserted into the patient end, while the other end is sealed with the help of a hot cautery. The inflator is non-breakable and weightless; the inflation is limited to $6-8$ c.c., and overinflation of the cuff is difficult. The ball-shaped pressure chamber of the Abbott blood pump can be used for the same purpose.

Department of Anaesthesia, Unıversity of Western Ontario, and Victoria Hospital, London, Ontario.

†This item has been contributed by Dr. R. R. Aitken, Senior Associate, Department of Anaesthesia. 


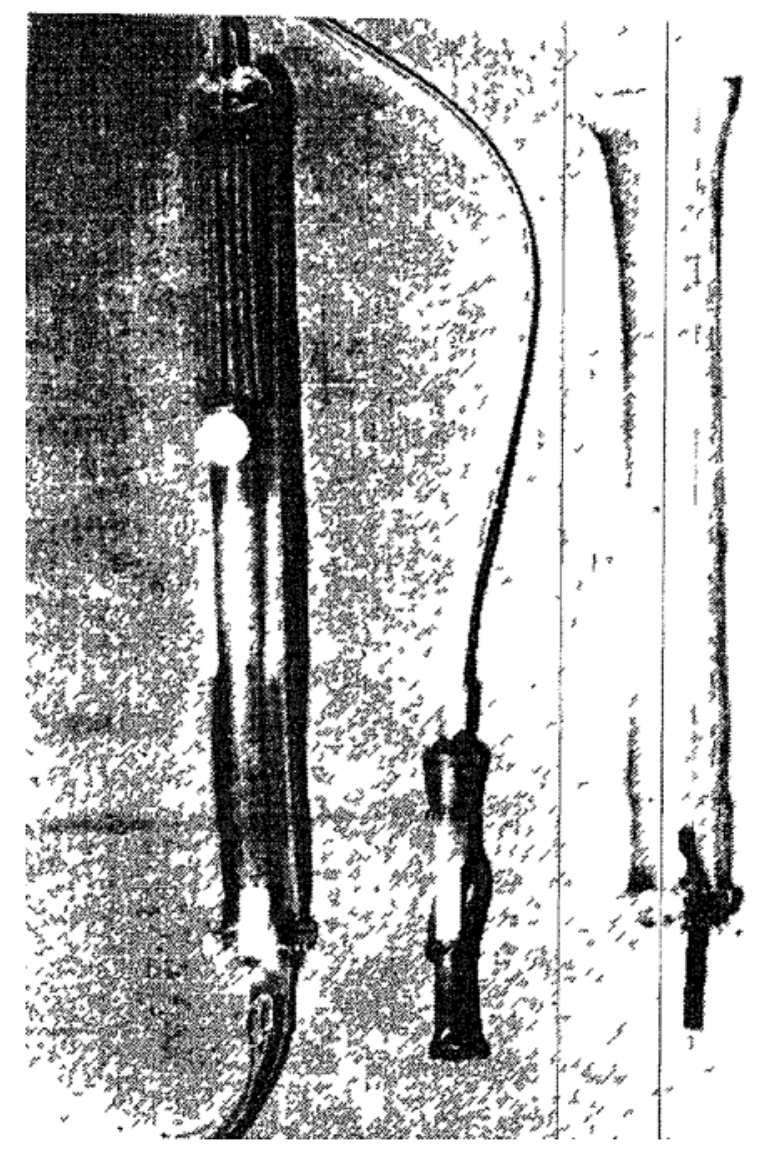

FIGURe 1. Plastic cuff inflator (right) made from Baxter transfusion set $\mathrm{R} 49$.

2. The Macintosh Spray can be improved considerably and made longer lasting by replacing all its rubber parts with discarded plastic tubing. Using a Baxter R 33 injection set, a piece of tubing from an R 49 set, and a 20-gauge stiff plastic endotracheal tube (Foregger) this instrument can be made more efficient and durable.*

3. The idea of a simplified Ayre's tube is also associated with disposed.plastic. A piece of Tygon tubing, discarded from the pump-oxygenator, cut ends from endotracheal tubes, and the plastic connector to the intravenous bottle from an R 49 Baxter set as adaptor for the inflow tubing are all the requirements for a light-weight and very useful piece of equipment in paediatric anaesthesia. ${ }^{1}$

4. Continuous monitoring of the heart sound in children has become an established and occasionally life-saving procedure. The usual metal stethoscope is difficult to fasten to an infant's chest and clumsy to handle. The bottom of an "Anectine Flow Pack" (Burroughs Wellcome) and intravenous tubing make a light-weight stethoscope (Fig. 2), which is easily strapped to an infant's chest. $千$

* This item has been contributed by Dr. R. R. Aitken, Senior Associate, Department of Anaesthesia.

TDr. J. M. Stewart, Instructor in the Department of Anaesthesia, made the first model of this plastic stethoscope. 


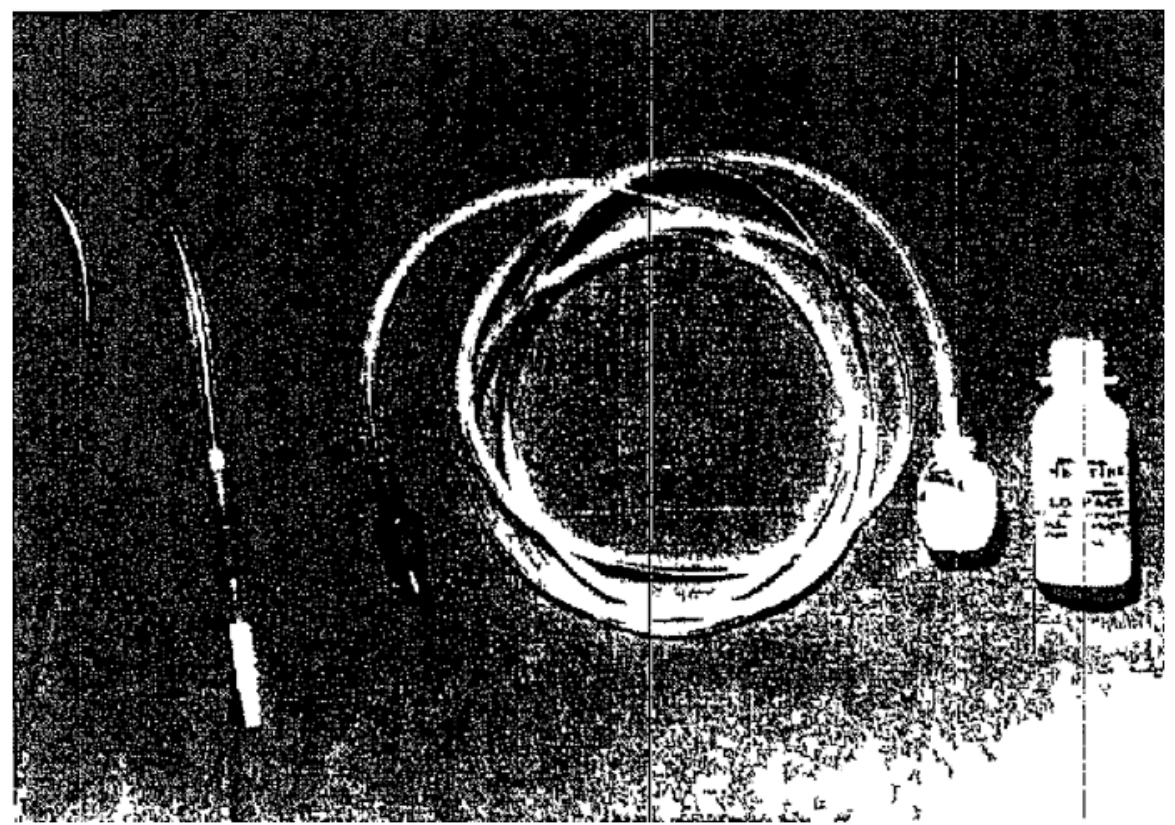

Ficune 2 Stethoscope to monitor heartsounds in infants made from discorded infusion set and an Anectine Flo Pack ( $B W$ )

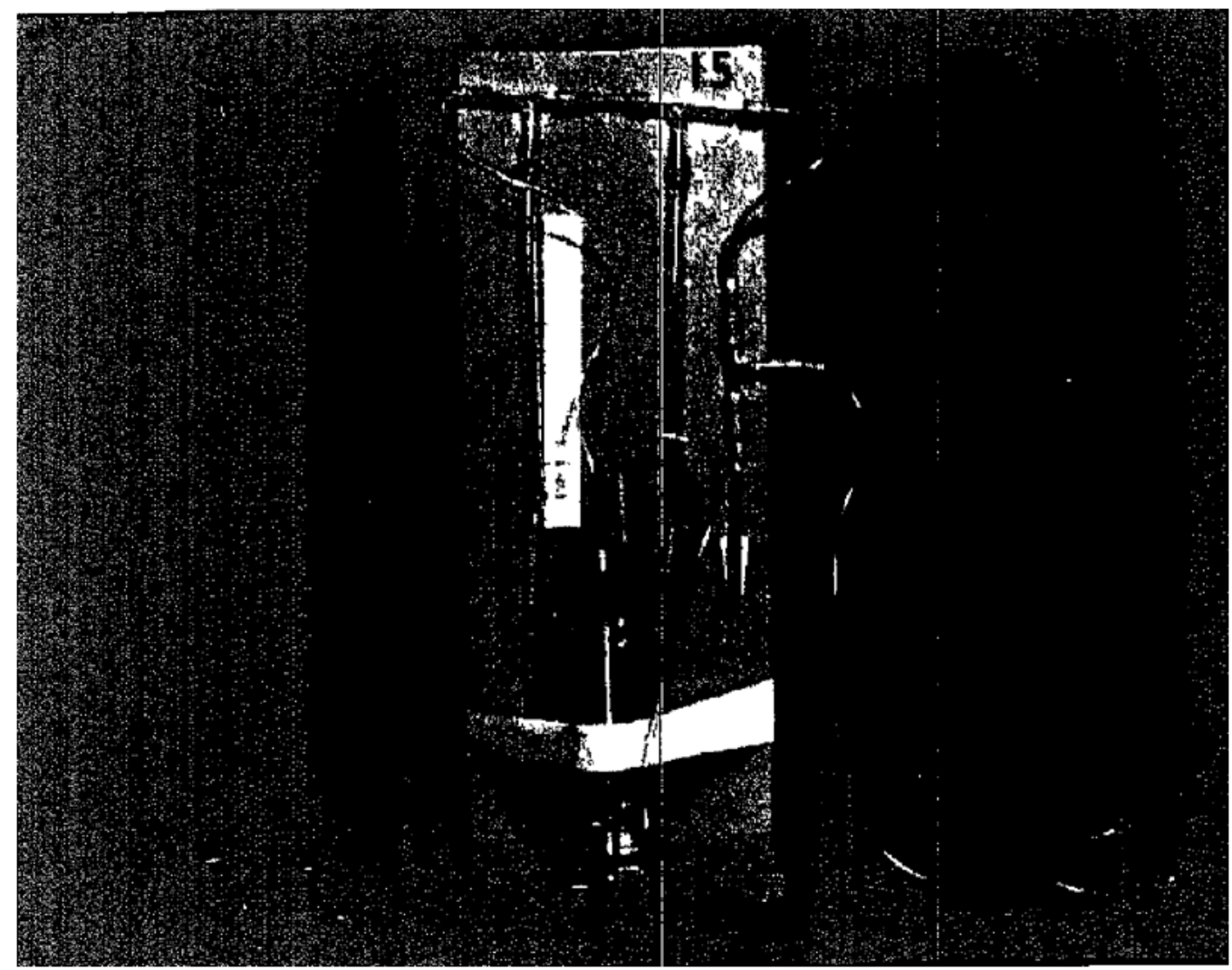

Figune 3 A simple anaesthetic machine for the admunstration of ether to laboratory animals 
The rubber injection site of a Baxter intravenous set makes an acceptable earpiece. As a precordial stethoscope it can be used only in children, but it also works well for the auscultation method of blood pressure determination.

5. A Resident in our Department, faced with the problem of anaesthetizing rabbits with ether in the student laboratory, built himself a small gas machine for the administration of air-ether mixtures (Fig. 3)..$^{2}$ A 250-ml. saline bottle (Baxter) serves as vaporizer; various sizes of discarded plastic are used to make a water depression flow meter, to control the inflow of air or oxygen, and to lead the gas mixture to the animal. This simple combination of vaporizer and flow meter has been used satisfactorily in the student laboratory for the last two years to maintain ether anaesthesia in rabbits by nasopharyngeal insuffation or with an Ayre's technique to a tracheotomy tube; it also has found application in investigative procedures requiring ether anaesthesia in small animals. The apparatus is admirably suited for teaching medical students the basic principles of inhalation anaesthesia and of the anaesthetic gas machine. It has effectively reduced the anaesthetic mortality of rabbits in our laboratory.

\section{SUMMARY}

A brief description is given of five "home-made" items used in our Department. "Disposed" plastic was the main material used to make a cuff inflator, a lightweight Ayre's tuibe, a precordial stethoscope for children, to rebuild the Macintosh spray, and to construct a simple gas machine for the student laboratory.

\section{RÉSUMÉ}

Nous avons décrit cinq appareils que nous avons faits nous-mêmes et que nous employons dans notre service. Nous avons employẻ du plastique destiné aux rebuts pour: (1) faire des ballonnets, (2) faire un tube de Ayre léger, (3) faire un stéthoscope précordial pour enfant, (4) reconstruire un gicleur de Macintosh et (5) construire une machine à anesthésie simple pour les étudiants au laboratoire.

\section{ACKNOWLEDGMENTS}

I wish to thank my colleagues for their contribution and for permission to publish it. Dr. J. M. Cox gave valuable assistance.

\section{REFERENCES}

1. Lewis, Audrey \& Spoerel, W. E. A Modification of Ayre's Technique. Can. Anaesth. Soc. J. 8: 501 (1961).

2. WaLker, F. To be published. 